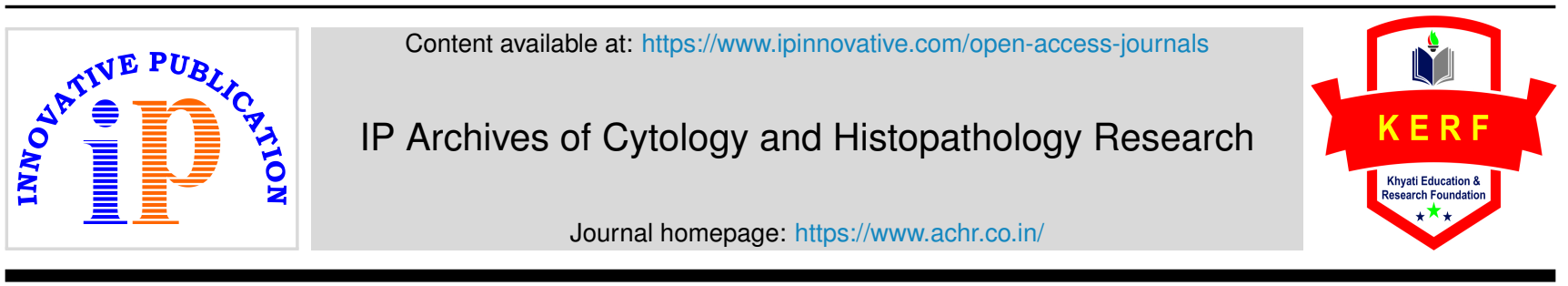

Original Research Article

\title{
A comparative study of the utility of cell block technique versus conventional smear cytology in pleural fluid cytology
}

\author{
Shwetha J H ${ }^{1}$ *, Sivarama Krishnaboddu ${ }^{1}$ \\ ${ }^{1}$ Dept. of Pathology, Jaya Jagadguru Murugarajendra Medical College, Davanagere, Karnataka, India
}

\section{A R T I C L E I N F O}

\section{Article history:}

Received 19-03-2021

Accepted 23-03-2021

Available online 03-04-2021

\section{Keywords:}

Cell block

Conventional smear

Pleural effusion

\begin{abstract}
A B S T R A C T
Background: The cytological examination of serous effusions has been universally accepted and a positive diagnosis is considered as a definitive diagnosis. It helps in staging, prognosis and management of the patients in malignancies and also helps to differentiate inflammatory and non - inflammatory lesions. The main diagnostic dilemma is to differentiate between reactive mesothelial cells from that of malignant cells in our routine practice.

Aims: To compare the morphological features of the conventional cytology with that of the cell block technique.

Materials and Methods: The study was conducted in the cytology section of the department of Pathology. Seventy five fluid samples were subjected to diagnostic evaluation for over a period of two years (August 2019 to February 2021). Along with the conventional smears, cell blocks were prepared using $10 \%$ alcohol - formalin as a fixative agent.

Results: Cellularity and yield for malignancy was more by the cell block technique.

Conclusion: The cell block technique provides high cellularity, better architectural patterns, morphological features and an additional yield of malignant cells when compared with that of conventional smear cytology.

(C) This is an open access article distributed under the terms of the Creative Commons Attribution License (https://creativecommons.org/licenses/by/4.0/) which permits unrestricted use, distribution, and reproduction in any medium, provided the original author and source are credited.
\end{abstract}

\section{Introduction}

Cytological examination of serous fluids is a commonly performed investigation. The accurate differentiation of malignant cells with reactive mesothelial cells is a diagnostic problem in conventional cytological smears. The cell block technique is one of the oldest methods for the evaluation of body cavity fluids. ${ }^{1}$ A new method of cell block preparation was used by using $10 \%$ alcohol- formalin fixative. The main advantages of the cell block technique are preservation of tissue architecture and obtaining multiple sections for special stains and immunohistochemistry. ${ }^{2}$

\section{Materials and Methods}

Pleural fluids were collected for cytological examination in the cytology section of the department of Pathology,

\footnotetext{
* Corresponding author.

E-mail address: shwetha024@gmail.com (Shwetha J H).
}

from August 2019 to February 2021. Ten milliliters of fresh pleural fluid sample was received. It was divided into two equal parts of five milliliters each. One part was subjected to conventional smear cytology and the other part for the cell block preparation.

\subsection{Conventional smear technique}

The five milliliter sample was centrifuged at $2500 \mathrm{rpm}$ for 15 minutes. A minimum of two thin smears were prepared from the sediment. One smear was prepared after air drying and stained with the May - Grunwald- Giemsa stain. The other smear was immediately fixed in 95\% alcohol and stained with the Hematoxylin - Eosin stain.

\subsection{Cell block technique}

The five milliliter sample was centrifuged at $2500 \mathrm{rpm}$ for 15 minutes. The supernatant was discarded and the 
remaining sample was mixed with $3 \mathrm{ml}$ of $10 \%$ alcohol - formalin fixative. This sample was kept for one day. On the following day, the sediment containing the cell button of the pleural fluid sample was scooped out on the filter paper and this cell button sediment sample was processed along with other routine histopathological specimens. The paraffin embedded cell button (Cell block) sections of 4-6 micron thickness were prepared and stained with the hematoxylin and eosin stain. Special stains like periodic acid Schiff (PAS) and mucicarmine were performed wherever necessary.

\subsection{Interpretation of $C S$ versus $C B$}

The samples were studied in detail taking into account the available clinical data, various investigation reports and morphological details. The samples were categorized as benign, suspicious for malignancy, or malignant lesions. The various morphological criteria that were taken into account included the cellularity, arrangement of the cells (acini, papillae and cell balls) and the cytoplasmic and nuclear details. All these criteria were put together and used for classifying the various cytomorphological patterns. A comparative evaluation of CS versus $\mathrm{CB}$ technique was conducted.

\section{Results}

Seventy five pleural fluid samples were subjected to the $\mathrm{CS}$ and CB method techniques. The age ranged from 18 to 90 years. Maximum samples were from the 45-60 year age group $(23 \%)$. The least number of samples was from the age group of 18-27 years (3\%). Male patient samples (forty) outnumbered the female patient samples. Cellularity was more by the $\mathrm{CB}$ method when compared to the CS method. Architectural patterns such as glands, sheets, threedimensional cell clusters and cell balls were commonly observed in the CB method, whereas, singly scattered cells were predominant findings in CS.

After analysis of the above samples, they were categorized as benign, suspicious for malignancy or malignant samples. By the cell block method, an additional six cases were detected as malignant. These samples were reported as either suspicious for malignancy or benign samples on conventional smear cytology. In the conventional smears, out of five reported benign samples, two were reported as florid mesothelial hyperplasia, two samples were misdiagnosed, as the morphology was obscured by a hemorrhagic, dirty background, plenty of inflammatory cells and reactive mesothelial cells. One more sample was misdiagnosed as an inflammatory smear. However, these five samples were reported as malignant by the $\mathrm{CB}$ method. Out of the four samples that were reported as suspicious for malignancy in CS, two samples were diagnosed as malignant effusions and the other two as benign lesions by the $\mathrm{CB}$ method.

The malignant effusions were more common in females than males. The female-to-male ratio was 3:1 for malignant effusions. The most common primary identified was from the breast. Out of 20 cases of malignant pleural effusions, the primary was known in twelve cases, which included five cases of carcinoma breast from female patients and four cases of carcinoma of the lung (both from a male) and three cases of gastrointestinal tract (two from a male and one from a female patient). In the remaining eight cases, the primary could not be detected as the patients were lost to follow-up.

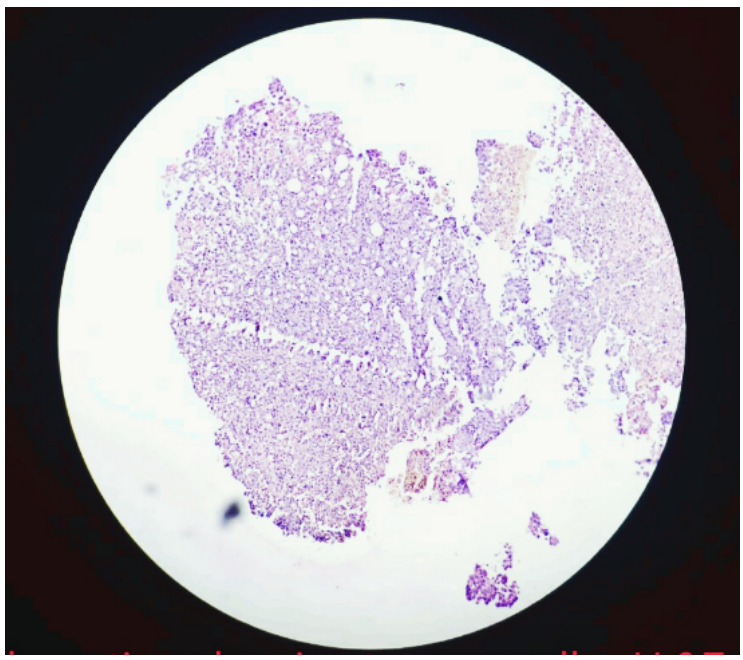

Fig. 1: Cell block showing tumor cells, H\&E stain, 10X.

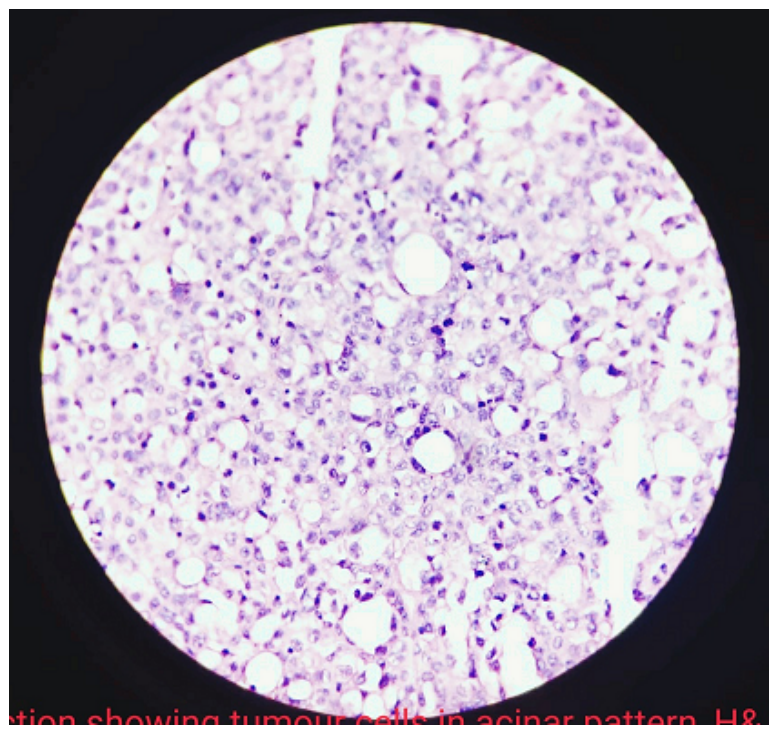

Fig. 2: Cell block section showing tumor cells inacinar pattern, H\&E stain, $40 \mathrm{X}$ 


\section{Discussion}

The cytological examination of serous effusions has increasingly gained acceptance in clinical medicine, to such an extent that a positive diagnosis is often considered the definitive test and obviates explorative surgery. It is important not only in the diagnosis of malignant lesions, but also helps in staging and prognosis. ${ }^{3}$

The development of malignant pleural effusion is a common complication of cancers like pulmonary and gastric carcinomas. ${ }^{4}$ Examination of fluids from the serous cavities of the body is an essential component of management in adult patients. Malignant neoplasms, especially lymphoid neoplasms, represent a major cause of death in children and in these cases cytological examination is very useful in their management. ${ }^{5}$

One of the most common problems in CS cytology is to distinguish reactive mesothelial cells from metastatic neoplasms. The difficulty is either secondary to marked atypia of mesothelial cells caused by the microbiological, chemical, physical, immunological, or metabolic insults to the serous membranes or to the subtle cytomorphological features of some malignant neoplasms, particularly welldifferentiated adenocarcinomas.The problem may become compounded by artifacts from poor fixation, preparation, or staining techniques. ${ }^{6}$ Although the preparation of CS is a much simpler procedure than that of paraffin sections, it has limitations, that is, lack of tissue architecture. In some cases, appreciation of tissue architecture make diagnosis easier. ${ }^{7}$ Others like reactive mesothelial cells, abundance of inflammatory cells and paucity of representative cells contribute to considerable difficulties in making conclusive diagnosis on conventional smears. ${ }^{8}$

Since the introduction of the CB technique by Bahrenburg nearly a century ago, it has been used routinely for processing fluids. In 1928, Zemansky concluded that the $\mathrm{CB}$ method was superior to the CS technique and that examination of materials other than pleural and ascitic fluids was unreliable. Cancer cells in the pleural or ascitic fluid are almost always indicative of metastatic cancer, as tumors arising from mesothelial cells lining these spaces are rare. When present, the tumor cells are usually numerous and frequently clusters may be found. The glandular forms are more reliable on CB. Earlier methods of CB preparations did not receive much attention, probably due to the lack of standardized technique. In fact the main problem with the $\mathrm{CB}$ preparation is the risk of losing material during preparation. Some researchers used agar, plasma/thromboplastin to bind the sedimented cells, but they have some disadvantages. 7,8

The advantages of the $\mathrm{CB}$ procedure include:

1. Recognition of histological patterns of diseases that sometimes cannot be identified reliably in conventional smears.
2. Possible to study multiple sections by routine staining, special staining and immunocytological procedures.

3. Less cellular dispersal, which permits easier microscopic observation than do traditional smears.

4. Less difficulty in spite of background showing excess blood on microscopic observation.

5. Possibility of storing slides for retrospective studies. Storage of the CS is a practical problem. ${ }^{9}$

For this reason, an attempt was made to prepare and analyze both CS and CB from the same specimen. Cell blocks may provide diagnostic information complementary or additional to that obtained from an examination of the cell smears. However, morphological preservation is often unsatisfactory in cell blocks processed by routine schedules used for surgical specimens. If the usefulness of a cell block is to be maximized, fixation and processing of the samples has to be modified so that the morphology approaches that of the conventional paraffin sections of the surgical specimens. ${ }^{7}$ In our study, we used $10 \%$ alcohol-formalin as a fixative for the CB preparation.

Apart from increased cellularity, better morphological details were also obtained with $\mathrm{CB}$, which included, preservation of the architectural patterns such as, cell balls, papillae and three-dimensional clusters, better nuclear and cytoplasmic preservation, intact cell membrane and crisp chromatin details. All these features increased the sensitivity of the diagnosis of malignancies by the CB methods, which were reported as negative in CS.

Reactive mesothelial cells have in the past been responsible for simulating malignancy in CS, largely due to the formation of rosettes, pseudoacini, or acini, with or without the presence of prominent nucleoli. Similar findings were noticed in the Dekker and Bupp study. ${ }^{3}$ This CB is a valuable tool in the evaluation of well-differentiated adenocarcinomas such as tumors of the breast, lung, or gastrointestinal tract. These tumors have few malignant characters in CS, while the presence of true acini is seen in the $\mathrm{CB}$, together with mucin, when stained for mucin, and are indicative of malignancy. The other advantage of $\mathrm{CB}$ is concentration of cellular material in one small area that can be evaluated at a glance with all cells lying in the same focal plane of the microscope. It bridges the gap between cytology and histology. ${ }^{3}$

An additional yield for malignancy is similar to the results of the Dekkar and Bupp ${ }^{3}$ study. They reported that samples obtained by the combined $\mathrm{CB}$ and $\mathrm{CS}$ techniques for malignant lesions were double that of the CS technique only.

The present study results for primary lesions were correlating with the Sears and Hajdu ${ }^{4}$ and Johnston ${ }^{10}$ studies. Sears and $\mathrm{Hajdu}^{4}$ reported that the most common primary neoplasms causing pleural effusions were carcinoma of the breast (24\%), followed by lung (19\%) and lymphoreticular system (16\%), and in $15 \%$ of the cases 
the primary site was unknown. In our study for pleural fluid analysis, carcinoma of the breast $(25 \%)$ was the most common primary followed by primary in the lung $(20 \%)$ and gastrointestinal tract $(15 \%)$ and in $40 \%$ of the cases the primary site was unknown.

The sections from CB provided additional information for a definite diagnosis, as it allowed recovery of minute cellular material and was valuable for histochemical and immunohistochemical methods. ${ }^{9,11}$

To conclude, our present study results showed that the cellblock technique, by using $10 \%$ alcohol-formalin as a fixative, was a simple, inexpensive method, and did not require any special training or instrument. The $\mathrm{CB}$ method yielded more cellularity and better architectural patterns which improved the diagnosis of malignancy. Multiple sections could be obtained if required for special stain or an Immunohistochemistry (IHC) study. Therefore, the $\mathrm{CB}$ technique could be considered as a useful adjuvant in evaluating fluid cytology for a final cytodiagnosis, along with the routine CS method. ${ }^{12}$

\section{Conflicts of Interest}

All contributing authors declare no conflicts of interest.

\section{Source of Funding}

None.

\section{References}

1. Wojcik EM, Selvagi SM. Comparison of smears and $\mathrm{s}$ in the fine needle aspiration diagnosis of recurrent gynecologic malignancies. Acta Cytol. 1991;35(6):773-779.

2. Nathan NA, Narayan E, Smith MM, Horn MJ. Cytology-improved preparation and its efficacy in diagnostic cytology. Am J Clin Pathol. 2000;114(4):599-606.
3. Dekker A, Bupp PA. Cytology of Serous Effusions: An Investigation into the Usefulness of Cell Blocks versus Smears. Am J Clin Pathol. 1978;70(6):855-60. doi:10.1093/ajcp/70.6.855.

4. Sears D, Hajdu SI. The cytologic diagnosis of malignant neoplasms in pleural and peritoneal effusions. Acta Cytol. 1987;31(2):85-97.

5. Wong JW, Pitlik D, Abdul-Karim FW. Cytology of Pleural, Peritoneal and Pericardial Fluids in Children. Acta Cytol. 1997;41(2):467-73. त01:0. $159 / 000332540$

6. Price BA, Ehya H, Lee JH. Significance of pericellular lacunae in cell blocks of effusions. Acta Cytol. 1992;36(3):333-40.

7. Kung IT, Yuen RW, Chan JK. Technical notes.Optimal formalin fixation and processing schedule of cell blocks from the fine needle aspirates. Pathol. 1989;21(2):143-5.

8. Mezger J, Stotzer O, Schilli G, Bauer S, Wilmanns W. Identification of carcinoma cells in ascitic and pleural fluid. Comparison of four panepithelial antigens with carcinoembryonic antigen. Acta Cytol. 1992;36(1):75-81.

9. Kushwaha R, Shashikala P, Hiremath S, Basavaraj HG. Cells in pleural fluid and their value in differential diagnosis. Jf Cytol. 2008;25(4):43138. 101:010103/09/0-93/1.50/99.

10. Johnston WW. The malignant pleural effusion. A review of cytopathologic diagnoses of 584 specimens from 472 consecutive

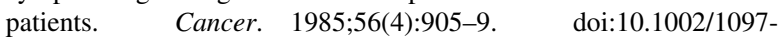
$0142(19850815) 56: 4<905:: a i d-c n c r 2820560435>3.0 . c 0 ; 2-u$.

11. Leung SW, Bedard YC. Methods in Pathology: Simple mini block technique for cytology. Mod Pathol. 1993;6:630-2.

12. Mishra RK, Sharma A, Goyal V, Goyal V, Thapar M. Critical analysis of cell block versus smear examination in effusions. J Cytol. 2009;26(2):60-4. 100:10-4103/09/0-93/1.552223.

\section{Author biography}

Shwetha J H, Associate Professor

Sivarama Krishnaboddu, Post Graduate Resident

Cite this article: Shwetha J H, Krishnaboddu S. A comparative study

of the utility of cell block technique versus conventional smear cytology in pleural fluid cytology. IP Arch Cytol Histopathology Res

2021;6(1):18-21. 